\title{
Relação entre políticas em educação e práticas escolares no ensino médio integrado à educação profissional
}

\author{
The relationship between education policies and school practices in secondary \\ education integrated with professional education \\ Relación entre las políticas educativas y las prácticas escolares en la escuela \\ secundaria integrada a la educación profesional
}

RACHEL COSTA DE AZEVEDO MELLO Orcid Id: http://orcid.org/0000-0002-5726-155 Universidade Federal Rural de Pernambuco JAQUELINE MOLL

Orcid Id: http://orcid.org/0000-0001-5465-178X Universidade Federal do Rio Grande do Sul

\begin{abstract}
Resumo: O presente artigo tem como objetivo analisar a atuação de gestores, professores e estudantes nas práticas escolares, diante das orientações das políticas em educação e dos desafios do cotidiano escolar no ensino médio integrado à educação profissional no contexto brasileiro. Tendo como referencial teórico metodológico, os estudos de Stephen Ball, o Ciclo de Políticas, a pesquisa foi realizada em uma escola pública de ensino médio integrado em Pernambuco, na qual utilizamos a análise da política educacional, observações diretas e registro em diário de campo e entrevistas. A partir da categoria teórica "atuação", analisamos as práticas dos gestores, professores e estudantes e identificamos que as categorias empíricas, "tempo e espaço escolar", assim como, "diálogo e participação" são fundamentais para repensarmos as políticas em educação e as práticas escolares no ensino médio integrado à educação profissional.
\end{abstract}

Palavras-chave: Políticas em educação. Práticas escolares. Ensino médio.

\begin{abstract}
This article aims to analyze the performance of managers, teachers, and students in school practices, given the guidelines of education policies and the challenges of everyday school in High School Integrated with professional education in the Brazilian context. Using Stephen Ball's studies, the Policy Cycle, as a theoretical and methodological reference, the research was carried out in a public integrated high school in Pernambuco, in which we used the analysis of educational policy, direct observations, and record in a field diary and interviews. Based on the theoretical category of performance, we analyze the practices of managers, teachers and students, and identify that the empirical categories, time and school space, as well as dialogue and participation, are fundamental to rethinking policies in education and school practices in Integrated High School professional education.
\end{abstract}

Keywords: Education policies. School practices. High school. 
Resumen: Este articulo tiene como objetivo analizar el desempeño de gerentes, maestros y estudiantes en las prácticas escolares, dadas las pautas de las políticas educativas y los desafíos del cotidiano escolar en la enseñanza secundaria integrada a la educación profesional en el contexto brasileño. Utilizando los estudios de Stephen Ball, Ciclo de Políticas, como marco teórico y metodológico, la investigación se llevó a cabo en una escuela secundaria pública integrada en Pernambuco, en la que utilizamos el análisis de la política educativa, observaciones directas y registros en un diario de campo y entrevistas con base en la categoría teórica actuación; analizamos las prácticas de gerentes, maestros, estudiantes e identificamos que las categorías empiricas, el tiempo y el espacio escolar, así como el diálogo y la participación son fundamentales para repensar las políticas en educación y prácticas escolares en la escuela secundaria integrada a la educación profesional.

Palabras clave: Politicas educativas. Prácticas escolares. Escuela secundaria.

\section{INTRODUÇÃO}

A vivência de políticas democráticas em educação no cotidiano escolar diz muito sobre o comprometimento com a escolarização como direito de todos e de todas e sobre a possibilidade de equidade e justiça social. O presente artigo tem como objetivo analisar a atuação de gestores, professores e estudantes nas práticas escolares, diante das orientações das políticas em educação e dos desafios do cotidiano escolar no ensino médio integrado (EMI) à educação profissional no contexto brasileiro. Significa saber como esses "atores" materializam os textos da política à prática.

Com esse objetivo, apoiamo-nos em um referencial teórico-metodológico para fundamentar a análise, indo de Paulo Freire, Henry Giroux e Jaqueline Moll a Stephen Ball e Jefferson Mainardes, respectivamente, no intuito de articular um referencial teórico a um referencial analítico. O foco da análise, nesta pesquisa, são as práticas e as políticas de EMI, por considerá-lo um caminho que abre a possibilidade de integração do ensino médio à formação profissional, tendo em vista que o ensino médio/secundário brasileiro foi marcado, historicamente, por um sistema dualista, com formações educativas diferenciadas para ricos e pobres, o que contribuiu para desigualdades educacionais e sociais e para permanência de um sistema social injusto, que vem sendo normalizado.

Para Nosella (2015, p. 132), o ensino médio no Brasil foi permeado pela polêmica sobre sua identidade, seguindo "a noção de sistema dual, reflexo da estrutura classista fundamental da sociedade." De fato, no Brasil, o longo período do colonialismo e de escravidão retardou o processo educacional para o povo: 
[...] continuamos presos a uma sociedade de classes, onde, não obstante $o$ discurso em contrário e os avanços ocorridos, o aprendizado intelectual de excelência é uma reserva das elites, algo bem próximo à formação dos jovens nobres dos latifúndios da Colônia e do Império, enviados a Lisboa e Coimbra. (FRIGOTTO; CIAVATTA, 2011, p. 620).

Na lógica dualista da estrutura societária, a profissionalização é destinada à juventude pobre, sem acesso aos processos estendidos de escolarização e o ensino propedêutico para as juventudes das camadas médias e altas, destinadas ao ensino superior. Diante da histórica fragmentação do ensino médio brasileiro, políticas públicas em educação, nas duas últimas décadas vêm favorecendo ações e tentativas de mudanças, a partir de novas diretrizes, voltadas à garantia do direito à educação da juventude. A política de ensino médio integrado à educação profissional, iniciada no Brasil em 2004, com o decreto no 5.154/04, é uma dessas tentativas que aponta para uma mudança, enfrentado o dualismo, ao propor uma formação unificada para juventude (BRASIL, 2004).

[...] reflexões conduziram ao entendimento de que uma solução transitória e viável é um tipo de ensino médio que garanta a integralidade de uma educação básica, ou seja, que inclua os conhecimentos científicos produzidos e acumulados historicamente pela sociedade, como também objetivos adicionais de formação profissional numa perspectiva da integração dessas dimensões. (MOURA, 2007, p. 19, grifo nosso).

Com essa perspectiva, o EMI, enquanto política em educação, caminha na direção de superar o dualismo que marcou a política de ensino médio no Brasil, apontando a possibilidade de um novo percurso escolar para a educação da juventude, a partir de uma política pública que visa à equidade e já é uma realidade em muitos estados, inclusive em Pernambuco.

Assim, buscamos responder à questão norteadora da pesquisa: como gestores, professores e estudantes "atuam" em relação à política em educação, nas práticas escolares no ensino médio na modalidade integrado? Para tal, buscamos, como procedimento de pesquisa, analisar a relação entre políticas e práticas escolares no cotidiano de uma escola pública em Pernambuco, "palco" onde acontece o processo de atuação. 


\title{
CICLO DE POLÍTICAS: UMA CHAVE PARA COMPREENSÃO DAS POLÍTICAS E PRÁTICAS ESCOLARES
}

Tendo como objetivo analisar a relação entre políticas e práticas escolares, identificando a atuação de gestores, professores e estudantes, adotamos o referencial analítico do sociólogo inglês Stephen Ball e colaboradores: o Ciclo de Políticas: "[...] o ciclo de políticas é um método. Ele não diz respeito à explicação das políticas. É uma maneira de pesquisar e teorizar as políticas". (BALL, 2009 apud MAINARDES; MARCONDES, 2009, p. 304-305)

Assim, o Ciclo de Políticas constitui um referencial para a análise crítica da trajetória de programas e políticas educacionais, composta por diferentes contextos, mas relacionados. Segundo Mainardes (2006), Ball estabeleceu, inicialmente, três contextos: o de influência, o da produção de texto, o da prática, e, posteriormente, mais dois: o dos resultados/efeitos e o de estratégia política. Nesta pesquisa, a análise se concentrará nos contextos da produção de texto e no da prática, a partir da categoria "atuação". Ball (1994) defende o conceito de atuação e não simplesmente de "implementação" de políticas, na prática das escolas.

\begin{abstract}
Nosso uso do conceito de atuação baseia-se nas premissas relacionadas que as políticas não lhe dizem normalmente o que fazer, elas criam circunstâncias nas quais uma gama de opções disponíveis para decidir o que fazer são estreitadas ou alteradas ou metas e resultados particulares são definidos (BALL, 1994, p. 19-20, grifo nosso).
\end{abstract}

O termo "atuação" se refere ao substantivo enactment que, em português, aproxima-se de uma "representação teatral" e remete também à tradução/ interpretação. Para Ball, a interpretação "é um compromisso com as linguagens da política, ao passo que a tradução está mais próxima às linguagens da prática" (MAINARDES, 2006, p. 69).

É quase como uma peça teatral. Temos as palavras do texto da peça, mas a realidade da peça apenas toma vida quando alguém as representa. E este é um processo de interpretação e criatividade e as políticas são assim. A prática é composta de muito mais do que a soma de uma gama de políticas e é tipicamente investida de valores locais e pessoais e, como tal, envolve a resolução de, ou luta com, expectativas e requisitos contraditórios - acordos e ajustes secundários fazem-se necessários. (BALL, 2009 apud MAINARDES, MARCONDES, 2009, p. 305, grifo nosso). 
Portanto, para captar a atuação dos “atores" escolares, a opção escolhida foi o estudo de caso, no qual utilizamos a análise textual discursiva (MORAES; GALIAZZI, 2006): dos documentos oficiais da política (leis, planos, normatizações, portarias, resoluções, decretos) e documentos específicos da escola (projeto político-pedagógico - PPP e regimento escolar); dos registros em diário de campo da observação direta do cotidiano escolar; das transcrições das entrevistas semiestruturadas (MINAYO, 1994) individuais e em grupos focais (GATTT, 2005).

Realizamos observações diretas com registro em diário de campo, além de captação de imagens em filmagens e fotografias e entrevistas semiestruturadas com: a equipe gestora (gestora, gestor adjunto e educador de apoio/coordenador pedagógico); cinco professores(as) das cinco áreas de conhecimento (sendo um professor do EMI de cada área); os estudantes dos $1^{\circ}, 2^{\circ}$ e $3^{\circ}$ anos do EMI (organizados em forma de três grupos focais, cada um com 10 a 12 estudantes); o coordenador de pesquisa educacional, representante da empresa da parceria público/privada que atua na escola.

Todo o levantamento de dados, nas análises empreendidas e no processo de sistematização, foi guiado pela categoria teórica "atuação", que possibilitou identificar categorias empíricas, surgidas a partir da análise textual discursiva do corpus (documentos) da pesquisa. Ao serem sistematizados, os dados encontrados levantaram temáticas recorrentes, tanto nos documentos, nas falas (entrevistas), quanto nas situações de atuação das políticas na prática (observação direta). Assim, o "tempo e o espaço escolar", além do "diálogo e participação" foram identificados como as categorias empíricas da pesquisa.

\section{CONTEXTOS DA PRODUÇÃO DE TEXTO E DA PRÁTICA: ANÁLISE DA RELAÇÃO ENTRE AS POLÍTICAS E PRÁTICAS ESCOLARES DO EMI NA ESCOLA}

Nesta pesquisa, consideramos o contexto da produção de texto e o contexto da prática, uma vez que a análise de ambos trará informações sobre a atuação dos gestores, professores e estudantes. Nesse sentido, sobre o contexto da prática, Ball e Bowe (1992 apud MAINARDES, 2006, p. 53) afirmam que:

[...] é onde a política está sujeita à interpretação e recriação e onde a política produz efeitos e consequências que podem representar mudanças e transformações significativas na política original. Para estes autores, o ponto-chave é que as políticas não são simplesmente "implementadas" dentro desta arena (contexto da prática), mas estão sujeitas à interpretação e, então, a serem "recriadas" [...]. 
A Educação Profissional Técnica de Nível Médio como política pública nacional, foi criada no período do governo de Luís Inácio Lula da Silva (20032006), através do decreto $n^{\circ} 5.154 / 2004$ - que substituiu e revogou o decreto $n^{\circ} 2.208 / 97$ - que determina, no artigo $4^{\circ}$ : "A educação profissional técnica de nível médio, [...] será desenvolvida de forma articulada com o ensino médio [...]." (BRASIL, 2004).

A política de EMI em Pernambuco acompanhou a política pública nacional do Ministério da Educação (MEC), passando a ofertar essa modalidade de ensino no estado em 2008, por meio da lei complementar $n^{\circ} 125$, de 10 de julho de 2008 (DUTRA, 2013). O Programa de Ensino Integral (PEI) teve como uma das suas finalidades: "Artigo $2^{\circ}$. IX - integrar o ensino médio à educação profissional, de modo a garantir a cidadania, componente essencial de trabalho digno e do desenvolvimento sustentável." (PERNAMBUCO, 2008). O PEI buscou reestruturar o ensino médio, como forma de reordenamento da rede estadual, criando as Escolas de Referência em Ensino Médio (EREMs) e as Escolas Técnicas de Ensino Médio (ETEs) (PERNAMBUCO, 2008). Nossa pesquisa tem como lócus uma ETE.

Assim, analisamos a política de EMI em Pernambuco com o propósito de situar a Escola Estudo de Caso, no contexto da produção do texto. Segundo Mainardes (2006, p. 52), esse contexto representa a "política" em forma de "textos legais oficiais e textos políticos, comentários formais ou informais sobre os textos oficiais, pronunciamentos oficiais, vídeos etc." Buscamos, na análise da política estadual de educação, extrair as orientações específicas que se referem ao trabalho pedagógico, que incidem nas práticas docentes e de gestão, funcionando como normatizações e orientações a serem seguidas. Eis as políticas selecionadas, em curso no ano de 2018: o Plano Estadual de Educação de Pernambuco (2015-2025) - PEE; lei complementar $n^{\circ} 125$, de 10 de julho de 2008; instrução normativa SEE n ${ }^{\circ}$ 08/2017; instrução normativa SEE no 09/2017; portaria SEE no 910, de 06 de fevereiro de 2018; PPP de 2018 da escola e seu regimento escolar.

Neste sentido, o regimento escolar da Escola Estudo de Caso orienta algumas condutas para o professor, entre as quais propõe, em relação às políticas em educação: "buscar conhecer as leis e respeitá-las; pensar em inovações e buscar suporte na LDB e demais leis para executá-las." E orienta, ainda, que: "quando discordar de alguma lei ou norma, buscar novas interpretações ou maneiras viáveis de modificá-las." Significa a abertura para o processo de atuação dos professores no contexto da prática.

No processo de atuação, identificamos duas categorias empíricas que se referem à organização da rotina escolar: tempo escolar e espaço/ambiente escolar. A atuação dos diferentes "atores" na "cena" escolar organiza-se nos tempos e 
nos espaços e concretiza-se no conjunto das práticas escolares, incluindo desde situações didáticas, como as aulas, passando pelos rituais da entrada na escola, de alimentação, os intervalos, as assembleias de estudantes, os conselhos de classe, as reuniões de gestores, de professores e de pais, os eventos culturais e esportivos, entre outras. Para Ball (2016 apud AVELAR, 2016, p. 7), esse conjunto de práticas é traduzido em "todos os tipos de atividades, todos os tipos de práticas, que pegam aquelas expectativas e as transformam em algo que seja trabalhável, factível e atingível."

Entendemos o tempo e o espaço escolar como categorias empíricas que interferem no trabalho pedagógico da escola como um todo, sendo determinantes na atuação das políticas e diante dos desafios postos no cotidiano escolar. Ball (2016 apud AVELAR, 2016, p. 11-12) chama a atenção para o espaço escolar como um aspecto geralmente negligenciado na análise das políticas:

[...] a maior parte das análises de política, particularmente aquelas de nível escolar ou institucional, você encontra muitas citações de pessoas falando coisas e, às vezes, descrições de pessoas fazendo coisas. Mas você raramente consegue ter uma noção de onde seja este lugar, como ele se parece. Presumidamente ele é um prédio, ou conjunto de prédios, mas você muito raramente tem qualquer noção da aparência deste prédio, das condições em que ele esteja, quais instalações ele possua, como eles estão estruturados, de que cor são pintados. Ele tem um playground para os alunos brincarem? Tem laboratório de ciências? Nós desmaterializamos a análise de políticas públicas, nós a arrancamos do seu contexto, neste sentido, não damos nenhuma noção de sua materialidade.

Quando refletimos sobre a rotina escolar, pensamos automaticamente nos usos dos tempos (de aulas, de intervalos, de reuniões etc.) e nos espaços, enquanto ambiências. Dizem respeito às condições objetivas do trabalho pedagógico, dando concretude às práticas escolares diárias na instituição escola, mesmo percebendo que, o tempo e o espaço/ambiente escolar nem sempre são registrados em pesquisas sobre políticas nas práticas escolares.

Então levar o contexto a sério [...] é rematerializar a política pública, dar a ela fundamentação literal e visceral em termos das instalações, pessoas e dinheiro. Há quantos professores? Quão experientes eles são? Qual é seu treinamento? Qual é seu passado? Quantos anos eles trabalharam com ensino? Nós não sabemos estas coisas! Nós também raramente incluímos uma noção dos artefatos da política - como pôsteres que estão pendurados, tecnologias que são usadas, como as salas estão organizadas, que seriam os atores "não humanos" dentro do processo de atuação. (BALL, 2016 apud AVELAR, 2016, p. 12). 
Segundo Cavaliere (2009, p. 51): “a escola fundamental brasileira, especialmente aquela voltada para as classes populares, sempre foi uma escola minimalista, isto é, de poucas horas diárias, pouco espaço e poucos profissionais." O minimalismo "imposto", historicamente, às escolas destinadas às crianças e jovens pobres, tanto em relação ao tempo (poucas horas), quanto às ambiências (precariedade) merece atenção enquanto objeto de análise em pesquisas sobre políticas públicas em educação.

Este é um processo social e pessoal, mas é também um processo material, na medida em que as políticas têm de ser "representadas" em contextos materiais. Se você tem uma escola com muitos recursos e muito dinheiro, professores muito experientes, alunos muito cooperativos, a "atuação" torna-se um pouco mais fácil do que na situação em que temos alunos com enormes dificuldades de aprendizagem, poucos recursos, instalações precárias, professores muito inexperientes. (BALL, 2016 apud MAINARDES; MARCONDES, 2009, p. 305).

Ao criticarmos a permanência histórica da "escola pobre para os pobres", estamos comprometidos com ideais de justiça social para todos e todas e com o papel propositivo das políticas públicas em educação nesta questão. Todavia, este não é o caso da escola em análise, muito pelo contrário: a Escola Estudo de Caso apresenta excelência, especificamente no quesito espaço/ambiente escolar, no projeto arquitetônico, o que repercute concretamente na organização do tempo escolar, mostrando o quanto o ambiente é parte estruturante na proposição de rotinas do trabalho pedagógico.

[...] a política educacional não é apenas o que pessoas dizem e fazem, mas política educacional é também sobre prédios e dinheiro, relações e poder e outras coisas. E como pesquisadores educacionais, pesquisadores de políticas públicas, precisamos nos engajar com estes aspectos de "o que é política". (BALL, 2016 apud AVELAR, 2016, p. 12).

$\mathrm{Na}$ Escola Estudo de Caso observamos que o cotidiano escolar é constituído por um ambiente arquitetônico destinado a ser escola, com ambientes escolares climatizados, equipados, espaçosos, iluminados, com equipamentos tecnológicos, mobilidade para novos arranjos de mobílias e áreas internas e externas de convivência. A diversificação e adequação de ambientes, equipamentos e materiais à escolarização são impactantes, num sentido positivo, na Escola Estudo de Caso, uma vez que propiciam um "clima" adequado às práticas com finalidades educativas (de estudo, pesquisa, ensino, organização e gestão), assim como, à criatividade, à vivência cultural e científica. $\mathrm{O}$ ambiente escolar foi reconhecido como relevante na fala dos estudantes: 
Sobre um aspecto bom, definitivamente, a estrutura; climatização em todas as salas, um ambiente muito bom. Tem quatro labs [laboratórios] com mais ou menos vinte computadores em cada um, labs de química e física. A estrutura é muito boa, não tenho o que reclamar. (ESTUDANTE DO $2^{\circ} \mathrm{ANO}$ ).

Ao discutir a avaliação do desempenho do ambiente escolar, Kowaltowski (2011) chama a atenção para o conforto ambiental (térmico, lumínico, acústico e funcional) e para o projeto paisagístico como fatores indispensáveis ao funcionamento dos ambientes escolares, que os deixam adequados ao ensino e às atividades educativas.

No entanto, o espaço no qual a vida escolar acontece, requer reflexões e análises dos seus "atores", que vão além do ambiente escolar. Analisar o contexto da prática envolve, para Mainardes (2006, p. 50) "identificar processos de resistência, acomodações, subterfúgios e conformismo dentro e entre as arenas da prática, e o delineamento de conflitos e disparidades entre os discursos nessas arenas." Nesse sentido, observamos na pesquisa que, apesar da satisfação dos "atores" com o espaço escolar, em relação à categoria empírica "tempo escolar", há um conflito em forma de queixa generalizada à extensa rotina de tempo integral, que aparece na fala dos estudantes e também dos professores e gestores, sobre o tempo total de $9 \mathrm{~h}$ na escola. E, principalmente, sobre o tempo destinado às aulas que, na Escola Estudo de Caso, é intercalado com três intervalos diários na rotina escolar do EMI: o primeiro (20min), é destinado à alimentação (lanche); o segundo (1h20min) é destinado ao almoço; e o terceiro (20 min), destinado ao lanche da tarde. Nesse sentido Krawczyk (2014, p. 30) levanta alguns questionamentos a respeito da rotina escolar integral para juventude:

Fala-se de extensão da jornada a partir de sete horas e já temos estados onde os alunos ficam 9,5 horas na escola. Duas horas a mais ou duas horas a menos não afeta a vida do estudante? O horário escolar é compatível com o relógio interno da adolescência? Que significa para um adolescente ficar numa instituição por tantas horas? Será que sua possibilidade de aprendizagem melhora? Que projeto pedagógico poderia otimizar esse tempo escolar? Existem projetos divergentes por trás das demandas por implementação da jornada completa?

Nas entrevistas nos grupos focais, estudantes de todos os anos levantaram a questão do "peso" da carga horária escolar de 9 h na rotina diária. Na realidade, não é somente da quantidade de horas de que estão se queixando, e sim do uso do tempo escolar. Depoimentos dos estudantes entrevistados atestam as contradições e os desafios advindos da categoria tempo escolar, nas suas vivências na rotina ampliada: 
Você consegue aprender muita coisa por causa do horário. É cansativo? É. Mas você consegue aprender tudo. O problema é que, às vezes, você tá muito cansado e o bom seria que as aulas fossem mais práticas. Você não dormisse nas aulas. Tem professores que deixam as aulas mais dinâmicas e colaborativas. (ESTUDANTE DO $1^{\circ}$ ANO).

Para Moll (2013, p. 41), a ampliação da jornada requer uma educação integral em tempo integral, que entenda que "conceber outros arranjos para a organização escolar implica a construção de outros olhares para o ato educativo e para responsabilidade advinda da existência de crianças e jovens entre nós." O "peso" da carga horária está prescrito na política estadual de educação que determina uma Matriz Curricular do Ensino Médio Integrado com 18 componentes curriculares, organizada em uma rotina diária de 9 aulas, 5 dias da semana.

A portaria SEE $n^{\circ}$ 910, de 06 de fevereiro de 2018, destina-se a publicar a Matriz Curricular do Ensino Médio Integrado em Pernambuco, composta por 11 componentes curriculares da Base Curricular Nacional (Linguagens e suas tecnologias; Matemática e suas tecnologias; Ciências da natureza e suas tecnologias; Ciências humanas e sociais e suas tecnologias); 1 componente da parte diversificada (Língua Estrangeira Inglês); 2 componentes das atividades complementares (Estudo Dirigido e aula de Educador Orientador - EO); e 4 componentes curriculares da formação técnica e profissional no curso técnico de Programação de Jogos Digitais, assim como no curso de Multimídia.

De acordo com o regimento escolar (art. 69): "O currículo configurase como o conjunto de valores e práticas que proporcionam a produção, a socialização de significados no espaço social e contribuem intensamente para a construção de identidades socioculturais dos estudantes." Apesar da imensa carga horária semanal composta por aulas, a ideia de currículo da Escola Estudo de Caso é uma concepção ampla e diversificada, permeada por "valores fundamentais interesse social". E, ainda, o $\ 3^{\circ}$ do regimento escolar dispõe sobre "a organização do percurso formativo, aberto e contextualizado", ou seja, como um processo construído considerando o contexto, os interesses e necessidades dos estudantes, incluindo os componentes curriculares centrais obrigatórios, mas propondo não somente a ampliação, mas também a diversificação dos tempos e espaços escolares.

Consideramos que a ampliação da jornada escolar, o turno integral, é fundamental para diversificação das formas de aprendizagens escolares, o que significa mais tempo para aprender e para a garantia dos componentes curriculares do ensino regular e do ensino técnico. É necessário ampliar o tempo escolar para garantia das aprendizagens dos estudantes de uma forma inovadora e diversificada, 
que não se reduza somente aos momentos de aula, mas inclua outras formas de aprender que alternem momentos de ensino, estudo, cultura, lazer, pesquisa e de descanso na rotina escolar, com atividades diversificadas: artísticas, culturais, científicas, tecnológicas e de intercâmbio de conhecimentos.

Nesse sentido, também as atribuições do trabalho docente necessitam de tempo não somente destinado ao ensino, mas para atividades individuais e coletivas de estudo, de pesquisa, de planejamento e avaliação, envolvendo a formação continuada em serviço. De acordo com a Instrução Normativa n ${ }^{\circ}$ 08/2017, os professores localizados nas Escolas Técnicas Estaduais de Pernambuco devem cumprir o tempo escolar em jornada de trabalho em regime integral, com carga horária de 40h semanais, distribuídas em cinco dias (Art. 14, \ $4^{\circ}$ ).

Ainda sobre o tempo escolar, de acordo com a Instrução Normativa n ${ }^{\circ}$ 09/2017, no seu artigo $6^{\circ}$, fica determinado: "A carga horária de professor regente deverá ser composta de: I - horas-aula em regência de classe; e II - horasaula atividade." E ainda, no seu artigo $7^{\circ}$ : "A hora-aula em regência de classe e a atividade de ensino-aprendizagem serão desempenhadas em sala de aula na escola ou em espaço pedagógico correlato.” Os professores destacam suas preocupações com o tempo escolar prescrito na política:

Tá dentro do programa que a gente tem que ficar o dia inteiro na escola, como professor concursado e estatutário. E aí eu convivo com os colegas, além de estar na sala de aula. Aí tem alguns momentos de aula atividade que a gente tá em convivência. Aí, nesses momentos de convivência, a gente troca muito. Era mais fácil pra gente, até uns dois anos atrás, integrar entre nós da área de humanas: da área de humanas com linguagens, por que a gente é amiga. Aí é mais fácil dialogar. (PROFESSORA DE HISTÓRIA).

A gente faz pesquisa pra disciplina, passa um tempo pra integrar como os professores do ensino regular: usa pra resolver questões do técnico [curso] com os outros professores. Passo muito tempo dedicada a inscrever os alunos em eventos externos, projetos. (PROFESSORA DE PROJETO INTEGRALIZADOR/ CURSO TÉCNICO).

Ainda sobre a fala/discurso dos professores, em relação ao tempo escolar, podemos observar que mais de um terço desta carga horária é destinada a atividades de estudo, planejamento e formação continuada: 
Art. 14. As horas-aula atividade corresponderão a 35\% (trinta e cinco por cento) da carga horária mensal para os(as) professores(as) com 200 (duzentas) horas-aula e a 33,3\% (trinta e três vírgula três por cento) da carga horária mensal para os(as) professores(as) com 150 (cento e cinquenta), horas-aula, cabendo à Equipe de Gestão e/ou Pedagógica da Unidade Escolar a responsabilidade, em conjunto com o(a) professor(a), de programar, acompanhar e registrar as atividades desenvolvidas, de acordo com o Art. $16 \$ 4^{\circ}$, Art.17 e Art. 44 do Estatuto do Magistério Público de Pernambuco (Lei Estadual $\mathbf{n}^{\circ}$ 11.329, de 16 de janeiro de 1996). $\int 1^{\circ}$ Do total das horas-aula atividade, serão destinadas à formação continuada, 30 (trinta) e 20 (vinte) horas-aula para os(as) professores(as) com carga horária mensal de 200 (duzentas) e 150 (cento e cinquenta) horas-aula, respectivamente. (PERNAMBUCO, 2017, grifo nosso).

As atuações dos gestores, da coordenação pedagógica e dos professores, em relação à organização dos tempos e espaços escolares na Escola Estudo de Caso mostram que são possíveis atuações criativas que solucionam problemas, mas é preciso repensar os tempos escolares e espaços destinados às aulas, alterando, especificamente, o modelo de aula. Constatamos que o tempo escolar precisa ser entendido melhor: significa que para garantir o direito à educação da juventude, a jornada escolar precisa ser redimensionada considerando as necessidades dos estudantes e suas vidas sobrecarregadas. Ao mesmo tempo, redimensionar tempos e espaços escolares não pode significar somente ampliação, mas diversificação e excelência no processo de ensino e aprendizagem no EMI.

Assim, identificamos no contexto da prática, a partir da análise textual discursiva das transcrições das entrevistas e dos registros de campo, as categorias empíricas "diálogo e participação". As situações pertencentes à rotina e à organização do trabalho pedagógico foram identificadas pelas regularidades observadas no cotidiano escolar, ou seja, aspectos recorrentes obtidos nas observações diretas e nas entrevistas. Nesse sentido, recorremos aos escritos de Paulo Freire e Henry Giroux, para fundamentar a importância do diálogo e da participação e para compreendermos os possíveis significados dessas práticas escolares.

Apresentamos as análises das políticas nas práticas escolares, considerando que a atuação pautada no diálogo envolve a concretude de situações democráticas no cotidiano escolar. Segundo Freire (1996, p. 136), “o sujeito que se abre ao mundo e aos outros inaugura com seu gesto a relação dialógica em que se confirma como inquietação e curiosidade, como inconclusão em permanente movimento da história." $\mathrm{Na}$ Escola Estudo de Caso, as práticas de sala de aula, as reuniões, os intervalos nos pátios e refeitórios - carregadas de lições de cidadania - foram identificadas como atuação dialógica, participativa e democrática de gestores, professores e estudantes. A construção de espaços de diálogo é fundamental para 
que a democracia seja aprendida e exercitada. Paulo Freire, no clássico "Pedagogia do oprimido" propõe a dialogicidade como a essência da educação como prática de liberdade:

[...] o diálogo é uma exigência existencial. E, se ele é o encontro em que se solidariza o refletir e o agir de seus sujeitos endereçados ao mundo a ser transformado e humanizado, não pode reduzir-se a um ato de depositar idéias de um sujeito no outro, nem tampouco tornar-se simples troca da, idéias a serem consumidas pelos permutantes. Não é também discussão guerreira, polêmica, entre sujeitos que não aspiram a comprometer-se com a pronúncia do mundo, nem com buscar a verdade, mas com impor a sua. Porque é encontro de homens que pronunciam o mundo, não deve ser doação do pronunciar de uns a outros. É um ato de criação. (FREIRE, 1987, p. 51).

Para Freire (1987, p. 44) “o educador já não é o que apenas educa, mas o que, enquanto educa, é educado, em diálogo com o educando que, ao ser educado, também educa." E ainda: "o diálogo, como encontro dos homens para a 'pronúncia' do mundo, é uma condição fundamental para a sua real humanização.” (FREIRE, 1987, p. 84). Giroux (1986), no clássico “Teoria crítica e resistência em educação", discute a "pedagogia da sala de aula e educação para cidadania", abordando questões relativas à relação entre professores e alunos, o que nos remete a temáticas debatidas por Paulo Freire:

Por fim, [...] o que parece estar em jogo no momento atual da história é a capacidade de futuras gerações pensarem e agirem de forma relevante aos antigos preceitos de liberdade e democracia. A tarefa de se desenvolver um modo de educação para a cidadania que se dirija a essa questão parece aterradora. Mas quando se olha as consequências de não atacá-la, aparece a possibilidade de um barbarismo tão terrível que não podemos fazer nada menos do que agir rápida e conscientemente, no espírito do que é justo, necessário e possível para enfrentar o desafio. (GIROUX, 1986, p. 265-266).

A participação pode ser concretizada na exposição dialógica das ideias, necessidades, questionamentos, dúvidas, propostas e dificuldades. A esse respeito, Giroux (1986) propõe a natureza ativa da participação dos estudantes no processo de ensino aprendizagem, que requer do professor uma intervenção também ativa que viabilize, na prática, a ideia de cidadania e democracia. Significa que "as escolas têm a responsabilidade de equipar os alunos com o conhecimento e habilidades de que eles precisarão a fim de desenvolver uma compreensão crítica de si mesmos, bem como o que significa viver em uma sociedade democrática." (GIROUX, 1986, p. 156). 
Nas práticas de gestão, esses momentos de exercício da democracia e diálogo foram vivenciados na atuação dos gestores: foi criada uma reunião semanal, a Reunião de Gestão, às segundas-feiras, com a equipe gestora, composta pela gestora, gestor adjunto/vice-diretor, educador de apoio/coordenador pedagógico, funcionários da secretaria, da alimentação, da limpeza, da biblioteca e da segurança, e coordenadores do curso técnico e da parceria público-privada.

\begin{abstract}
A gente identificou que a nossa comunicação era trucada, nem todo mundo sabia o que estava acontecendo na escola e tomavam iniciativas divergentes. Então, pensando em melhorar, ficar mais efetiva a nossa comunicação: temos hoje a reunião de gestão. (GESTORA).
\end{abstract}

Dentro desses espaços de reunião agente começa a fomentar, a construir essa dedicação e esse compromisso com todos. O principal desafio é, dentro da dificuldade de se comunicar, que é justamente trabalhar dentro dessas reuniões, o diálogo mais aberto e participativo. (GESTOR ADJUNTO).

Registradas em diário de campo e filmagens, essas reuniões de gestão têm caráter administrativo e pedagógico, em que são informadas e discutidas questões relacionadas à organização da rotina escolar: alimentação, segurança, secretaria, organização de horários, classes, ausência de algum professor, aniversariantes do mês, eventos, participação em eventos externos, materiais, parcerias, visitas externas, recursos financeiros, etc. nessas reuniões, os gestores mostraram-se servidores públicos atentos e interessados em resolver problemas escolares em todas as questões que envolvem a comunidade escolar.

A atuação da gestão esteve em sintonia com o PPP da escola, que determina: "prática de gestão, pais, alunos, professores e funcionários assumem sua parte de responsabilidade participativa no projeto da escola." Há razões que justificam a proposta de gestão democrática e compartilhada: "a escola deve formar para a cidadania e, para isso, ela deve dar o exemplo. A gestão democrática é um passo importante no aprendizado da democracia, pois a escola não tem um fim em si mesmo. Ela está a serviço da comunidade." E, ainda: "a gestão democrática pode melhorar o que é específico da escola, que é o seu ensino. A participação na gestão escolar proporcionará um melhor conhecimento do funcionamento da escola e de todos os seus atores." O PPP da escola determina, como código de conduta entre gestão e educadores, que se deve: "garantir os princípios da gestão democrática participativa”. E de acordo com o regimento escolar: 
Art. 15 - A Escola Técnica Estadual [...] terá uma gestão co-responsável, colegiada, participativa, cooperativa e transparente, com procedimentos que garantam a participação dos diferentes segmentos da comunidade escolar nos processos decisórios pedagógicos, administrativos e financeiros, orientados por diretrizes e princípios comuns.

Nas reuniões de gestão, é perceptível a abertura para o diálogo, uma vez que todos podem expor as questões de seu trabalho. Nesse processo, destaca-se a construção da autonomia da escola, pela qual se discute a relação entre escola e comunidade e a proposição de novos arranjos educativos, considerando diferentes coletivos em interação nos espaços educativos dentro e fora da escola. Também nas reuniões com os professores e a equipe gestora, são frequentes, os discursos da gestora sobre as práticas de gestão e docentes: "quando a gente luta por uma reunião com os professores, uma vez por mês, é pra avançar neste sentido. A gente senta pra conversar, discutir." A gestão criou também reuniões com os representantes de sala e com o grêmio escolar que, segundo a gestora: "colaboram com o processo de dialogicidade que temos na escola".

Assim, o trabalho pedagógico é o foco central das decisões administrativas da escola. É atuado de forma participativa por todo coletivo escolar e cobrado pela gestão como uma missão de todos e de cada um. A missão de educar é de todos:

Todos vão trabalhar como os estudantes, estar em contato com os estudantes. Então, de certa forma, todos vão estar educando, porque todos são adultos profissionais e, independente de uma hierarquia social do trabalho, você vai ter, desde os serviços gerais até a gestora, todos vão ser educadores, dentro de suas atribuições. Então, a ideia é fazer as pessoas se aproximarem, para debater, fazer a participação acontecer. Isso é fundamental dentro de uma cultura organizacional e daí todo mundo se sente comprometido e ninguém vai culpabilizar o outro, se caso, algo não der certo. (GESTOR ADJUNTO).

Sobre a sistemática da avaliação da aprendizagem, o regimento escolar estabelece, no seu Art. 124: "A avaliação da aprendizagem de caráter formativo predominando sobre o quantitativo e classificatório, adota uma estratégia de progresso individual e contínuo que favorece o crescimento do educando, preservando a qualidade necessária para a sua formação.” Um dos momentos de avaliação contínua da escola, em reuniões bimestrais, é o conselho de classe. A atuação de gestores, professores e estudantes no conselho de classe se apresentou como um momento coletivo de avaliação dos mais participativos da escola, realizado com os gestores, os professores e estudantes no auditório da escola. Podemos considerá-lo como uma avaliação processual que contempla a trajetória dos estudantes: 
É muito bom no final de cada unidade. A escola reúne dois representantes por turma, reúne todos os professores, junto com a coordenação e a diretoria para discutir o que foi passado. É o conselho [de classe]. Os próprios alunos que regem, apontando de cada professor a parte positiva e a parte negativa, o que funcionou e o que não funcionou e muitas vezes os professores estão abertos a novas ideias, se adaptam ao jeito dos alunos, mas muitas vezes os professores estão vidrados no modelo antigo. Eles reclamam por a gente reclamar deles. (ESTUDANTE DO $3^{\circ}$ ANO).

O conselho de classe, prática observada e registrada em diário de campo e filmagens, foi vivenciada como um espaço de diálogo entre professores e estudantes, supervisionado pela gestão. A dialogicidade perpassa todo processo de avaliação escolar, enquanto um momento em que os estudantes explicitam e explicam aos professores sua análise sobre os processos de ensino e aprendizagem: suas críticas, necessidades e sugestões. Como momentos de "catarse" e de intercâmbio foram registrados nas filmagens: professores atentos às análises dos representantes das classes. Nesses momentos de avaliação, há uma comunicação clara e respeitosa entre os pares e as críticas, de ambos os lados, colocadas e justificadas: professores avaliavam a turma e os estudantes e, ouviam as argumentações dos estudantes representantes das classes com atenção. Consideramos uma atuação dialógica e participativa, marcada pela troca de conhecimentos e experiências.

A atuação nas práticas docentes, nas salas de aula, mostrou professores e estudantes dispostos à interação e envolvidos socialmente e afetivamente. Foram muitas experiências pedagógicas pautadas no diálogo e na participação.

[...] a escola é um dos espaços sociais no qual a criança e o jovem poderão ampliar o espectro de suas relações e constituir-se identitariamente de forma gregária. O grupo de colegas com suas variações de gênero, raça, etnia, religião, agremiação esportiva, pode representar a ampliação das referencias familiares, permitindo o princípio de uma educação que caminhe na perspectiva dos direitos humanos, da superação dos conflitos por meio do diálogo, do respeito à diversidade e da superação das desigualdades. Para isso, é importante que a sala de aula constituase como uma espaço de diálogo, no qual diferentes lógicas, diferentes pontos de vista sejam explicitados e acolhidos, diferentemente do monólogo que caracteriza a lógica da mesmice e da homogeneização à qual nos referimos anteriormente. (MOLL, 2013, p. 47).

Entre as diversas aulas observadas, destaco as sequências de aulas de História, representativas de uma atuação participativa e dialógica: a metodologia de ensino foi socializada pelo professor de Geografia e adaptada pela professora de História para trabalhar com os seus conteúdos específicos. Nas aulas de História, essa nova metodologia, chamada por eles de "Rodízio", proporcionou o protagonismo e o intercâmbio de conhecimentos entre os estudantes. "Inúmeros 
professores, sós ou acompanhados de outros, nas dobras da cena escolar, produzem projetos, ações e reações que permitem a muitos estudantes um ambiente escolar de diálogo, de aprendizagens, de singularizações." (MOLL, 2013, p.44).

A atuação dos professores nas "aulas de EO" (educadores orientadores), como são chamadas pelos estudantes, acontecem simultaneamente, uma vez por semana, em todas as turmas na primeira aula das quartas-feiras. Na realidade não são "aulas", mas encontros para dialogar sobre temas relacionados à convivência e relações humanas na escola. Cada turma tem seu(s) educador(es) orientador(es), um ou dois professores, que propõem diálogos em grupos, jogos, dinâmicas de grupos, vivências com objetivo de conhecer os alunos, diálogos sobre temas referentes ao universo da juventude, além de ouvir histórias de vida, relatos, opiniões e resolver questões relacionadas à convivência estudantil na escola.

Uma prática que eu gosto muito, acho interessante, é o EO (o educador orientador), porque é uma espaço onde o professor pode ter um diálogo maior com a turma, para resolver os problemas pessoais mesmo. Mas tem que ser feito algumas melhorias ainda, porque os educadores tem que ter um treinamento sobre como agir melhor nesse tempo. Tem um horário, mas o educador tem que saber como mediar a situação, como resolver e aconselhar melhor os alunos. (ESTUDANTE DO $1^{\circ}$ ANO).

Assim, a participação e o diálogo, categorias empíricas da pesquisa, emergiram na atuação dos estudantes nos inúmeros projetos na Escola Estudo de Caso. Poderíamos chamar de projetos dialógicos ou participativos aqueles atuados por estudantes no cotidiano escolar, uma vez que promoveram a autoorganização e o protagonismo. Ficou visível que a coletivização das decisões promove a aprendizagem da democracia na prática, como um trabalho em grupo e um processo criativo, proporcionado pela formação de "times". De acordo como o PPP da escola: "todas as turmas serão divididas em times para o trabalho em sala de aula durante o ano letivo e, para formá-los será considerado opinionário.”

A questão dos times. Tem sempre os pontos positivos e negativos. A questão positiva é que ele prepara a gente para o mercado de trabalho, que tem que lidar com pessoas diferentes, de âmbitos diferentes de situações diferentes, então a questão do time, de ter um grupo que você vai ter que lidar com ele o ano todo é realmente bom. Só que, em compensação, também é mais cansativo porque torna nossa rotina mais exaustiva. (ESTUDANTE DO $3^{\circ}$ ANO).

A atuação dos estudantes, enquanto um processo de participação e auto-organização foi observada e registrada em diário de campo e filmagens nos diversos eventos da Escola Estudo de Caso: no festival de dança, nos jogos internos, no grêmio escolar e representantes de turma, na recepção dos alunos 
novos (projeto Gentileza gera gentileza). Observado em campo, esse projeto, é uma reunião conduzida e organizada em que participam alunos do $3^{\circ}$ ano em forma de roda de conversa com os alunos do $1^{\circ}$ ano. O objetivo é apresentar a escola e recepcionar os calouros para iniciar o diálogo sobre a escola, a rotina escolar, a convivência, as dificuldades e formas de superação.

A atuação dos estudantes foi observada nas práticas de integração entre o ensino regular e o técnico, que compreende uma série de intervenções pedagógicas, que vão desde as atividades do componente curricular Projeto Integralizador e seus desdobramentos em Seminários, que envolvem a atuação dos estudantes junto com os professores e coordenadores dos cursos técnicos.

Eu destaco que por ser uma escola técnica, tanto a parte técnica quanto o regular une os dois. A gente aprende no técnico e tenta usar no regular. Eu como sou de programação [curso técnico] às vezes eu uso alguma lógica de programação para resolver alguma coisa de matemática. Uso alguma coisa mais artística para resolver na área de humanas. Isso ajuda bastante. (ESTUDANTE DO $3^{\circ}$ ANO).

As atuações dos professores em processos de integração acontecem entre os componentes curriculares do ensino regular e o ensino técnico, assim como integração na formação continuada dos professores.

\section{CONSIDERAÇÕES FINAIS}

Encontramos, na Escola Estudo de Caso, em Pernambuco, um trabalho pedagógico conduzido com respeito mútuo entre educandos, educadores e gestores e atuações dialógicas, participativas e democráticas no cotidiano escolar. A atuação de cada coletivo envolvido com as práticas escolares na escola pesquisada indica uma multiplicidade de caminhos para efetivação do direito à educação via escola pública, legítima instituição social de sociedades democráticas e republicanas. A atuação dos coletivos significa a possibilidade de construção de um projeto de escolarização de qualidade, que promova aprendizagens significativas para os estudantes, visando enfrentar as desigualdades educacionais.

A pesquisa mostrou o quanto é necessária a reflexão sobre a relação entre práticas e políticas em educação e que, sem referenciais de escola bem-sucedida, não para alguns privilegiados, mas para todos os jovens, permaneceremos no mesmo lugar de país desigual e colonialista, numa situação de abismo social marcada pela exclusão dos "que não servem ao sistema" e cercados de pobreza e miséria, o que pode se tornar intransponível em poucos anos. Como resultados do estudo, concluímos que as categorias tempo e espaço escolar são fundamentais para repensarmos as políticas em educação e, o diálogo e a participação são 
expressões de políticas e práticas democráticas construídas por gestores, professores e estudantes no cotidiano escolar do Ensino Médio Integrado à Educação Profissional.

\section{REFERÊNCIAS}

AVELAR, Marina. Entrevista com Stephen J. Ball: uma análise de sua contribuição para a pesquisa em política educacional. Archivos Analíticos de Políticas Educativas, v. 24, n. 24, p.1-18, fev. 2016.

BALL, Stephen John. Education reform: a critical and post-structural approach. Buckingham, Philadelphia: Open University Press, 1994.

BRASIL. Decreto $\mathbf{n}^{\circ} \mathbf{5 . 1 5 4}$, de 23 de julho de 2004. Regulamenta o $\ 2^{\circ}$ do art. 36 e os arts. 39 a 41 da Lei no 9.394, de 20de dezembro de 1996, que estabelece as diretrizes e bases da educação nacional, e dá outras providências. Brasília, DF, 2004. Disponível em: http://www.planalto.gov.br/ccivil_03/_ato20042006/2004/decreto/d5154.htm. Acesso em: 13 abr. 2018.

CAVALIERE, Ana Maria. Escolas de tempo integral versus alunos em tempo integral. Em Aberto, Brasília, v. 22, n. 80, p. 51-63, abr. 2009. Disponível em: http://emaberto.inep.gov.br/index.php/emaberto/article/view/2220/2187. Acesso em: 12 jun. 2018.

DUTRA, Paulo Fernando de Vasconcelos. Educação Integral no Estado de Pernambuco: uma realidade no ensino médio. 2013. 98 f. Dissertação (Mestrado Profissional em Gestão e Avaliação da Educação Pública) - Universidade Federal de Juiz de Fora, Juiz de Fora, 2013. Disponível em: https://repositorio.ufjf.br/ jspui/handle/ufff/1114. Acesso em: 20 set. 2018.

FREIRE, Paulo. Pedagogia do oprimido. Rio de Janeiro: Paz e terra, 1987.

FREIRE, Paulo. Pedagogia da autonomia: saberes necessários à prática educativa. São Paulo: Paz e Terra, 1996.

FRIGOTTO, Gaudêncio; CIAVATTA, Maria. Perspectivas sociais e políticas da formação de nível médio: avanços e entraves nas suas modalidades. Educação\& Sociedade, Campinas, v. 32, n. 116, p. 619-638, jul./set. 2011. Disponível em: http://www.cedes.unicamp.br. Acesso em: 03 out. 2018. 
GATTI, Bernadete Angelina. Grupo focal na pesquisa em ciências sociais e humanas. Brasília: Líber Livro Editora Brasília, 2005.

GIROUX, Henry. Teoria crítica e resistência em educação: para além das teorias de reprodução. Petrópolis: Vozes, 1986.

KOWALTOWSKI, Doris. Arquitetura escolar: o projeto do ambiente de ensino. São Paulo: Oficina de Textos, 2011.

KRAWCZYK, Nora. Ensino médio: empresários dão as cartas na escola pública. Educação \& Sociedade, Campinas, v. 35, n. 126, p. 21-41, jan./ mar. 2014. Disponível em: http://www.scielo.br/scielo.php?pid=S010173302014000100002\&script=sci_abstract\&tlng=pt.Acessso em: 9 abr. 2018.

MAINARDES, Jefferson. Abordagem do ciclo de políticas: uma contribuição para a análise de políticas educacionais. Revista Educação \& Sociedade, Campinas, v. 27, n. 94, p. 47-69, jan./abr. 2006. Disponível em: https://www.scielo.br/pdf/ es/v27n94/a03v27n94.pdf . Acesso em: 8 jan. 2019.

MAINARDES, Jefferson; MARCONDES, Maria Inês. Entrevista com Stephen J. Ball: um diálogo sobre justiça social, pesquisa e política educacional. Revista Educação \& Sociedade, Campinas, v. 30, n. 106, p. 303-318, jan./abr. 2009. Disponível em: http://www.scielo.br/pdf/es/v30n106/v30n106a15.pdf. Acesso em: 8 jan. 2019.

MINAYO, Maria Cecília de Souza (org). Pesquisa social: teoria, método e criatividade. Petrópolis, RJ: Vozes, 1994.

MOLL, Jaqueline. Os tempos de vida nos tempos da escola: em que direção caminha a mudança? In: MOLL, Jaqueline (org.). Os tempos da vida nos tempos da escola: construindo possibilidades. Porto Alegre: Penso, 2013.

MOURA, Dante Henrique. Educação básica e educação profissional e tecnológica: dualidade histórica e perspectivas de integração. Holos, Rio Claro, a. 23, v. 2, p. 4-20, 2007. Disponível em: https://www2.ifrn.edu.br/ojs/index.php/HOLOS/ article/viewFile/11/110. Acesso em: 12 out. 2018. 
MORAES, Roque; GALIAZZI, Maria do Carmo. Análise textual discursiva: processo reconstrutivo de múltiplas faces. Ciência \& Educação, Bauru, v. 12, n. 1, p. 117-128, 2006. Disponível em: http://www.scielo.br/pdf/ciedu/v12n1/08. pdf. Acesso em: $1^{\circ}$ set. 2019.

NOSELLA, Paolo. Ensino médio unitário ou multiforme? Revista Brasileira de Educação, Rio de Janeiro, v. 20 n. 60, p. 121-142, jan./mar. 2015. Disponível em: http://www.redalyc.org/articulo.oa?id=27533496007. Acesso em: 3 maio 2019.

PERNAMBUCO. Instrução normativa SEE $\mathbf{n}^{\mathbf{0}} \mathbf{0 8} / 2017$. Estabelece normas e diretrizes para a organização do ano letivo das Escolas da Rede Estadual de Ensino do Estado de Pernambuco. Recife, 2017. Disponível em: http://www.educacao. pe.gov.br/portal/upload/galeria/14908/Instru\%C3\%A 7\%C3\%A30\%20 Normativa_09.2017.pdf. Acesso em: 30 abr. 2019.

PERNAMBUCO. Instrução normativa SEE $\mathbf{n}^{\circ}$ 09/2017. Estabelece normas e diretrizes para a elaboração do Calendário Escolar das Escolas da Rede Estadual de Ensino do Estado de Pernambuco, ano letivo 2018. Disponível em: INSTRUÇÃO\%20NORMATIVA\%20SEE\%20N\%\%2009.2017.pdf. Acesso em: 30 abr. 2019.

PERNAMBUCO. Lei Complementar $\mathrm{n}^{\circ} \mathbf{1 2 5}$ de 10 de julho de 2008. Cria o Programa de Educação Integral, e dá outras providências. Recife, 2008. Disponível em: legis.alepe.pe.gov.br/texto.aspx?id=5148\&tipo=TEXTOATUALIZADO. Acesso em: 30 abr. 2019.

PERNAMBUCO. Lei $\mathbf{n}^{\mathbf{0}} \mathbf{1 5 . 5 3 3}$ de 23 de junho de 2015. Plano Estadual de Educação de Pernambuco (2015-2025). Recife, 2015. Disponível em: http://www.educacao.pe.gov.br/portal/upload/galeria/10046/PLANO $\% 20$ ESTADUAL $\% 20$ DE $\% 20$ EDUCA $\%$ C3\%87\%C3\%83O_vers $\%$ C3\%A3o\%20 final_\%20Lei_\%20n\%C2\%BA\%2015.533\%20DOE.pdf.Acesso em: 30 abr. 2019.

PERNAMBUCO. Portaria SEE $\mathbf{n}^{\mathbf{0}} \mathbf{9 1 0}$ de 06 de fevereiro de 2018. Recife, 2018. Disponível em: http://200.238.105.211/cadernos/2018/20180207/1Pode rExecutivo/PoderExecutivo(2018020)pdf. Acesso em: 30 abr. 2019. 


\section{Rachel Costa de Azevedo Mello}

Doutora em Educação em Ciências pelo Programa de Pós-graduação de Educação em Ciências: química da vida e saúde da Universidade Federal do Rio Grande do Sul - UFRGS. Professora do Departamento de Educação da UFRPE - Universidade Federal Rural de Pernambuco. E-mail: racheldeazevedo@yahoo. com.br

\section{Jaqueline Moll}

Docente do Programa de Pós-Graduação de Educação em Ciências: Química da Vida e Saúde da Universidade Federal do Rio Grande do Sul - UFRGS. Docente do Programa de Pós- Graduação em Educação da Universidade Regional Integrada do Alto Uruguai e das Missões- URI. Doutora em Educação pela Universidade Federal do Rio Grande do Sul - UFRGS. E-mail: jaquelinemoll@ gmail.com 